\title{
Alterations in BDNF and NT-3 mRNAs in rat hippocampus after experimental brain trauma
}

\author{
R.R. Hicks ${ }^{\text {a }}$, S. Numan ${ }^{\text {b,1 }}$, H.S. Dhillon ${ }^{c}$, M.R. Prasad ${ }^{c}$, K.B. Seroogy ${ }^{b, *}$ \\ ${ }^{a}$ Department of Clinical Sciences, University of Kentucky, Lexington, KY 40536, USA \\ ${ }^{\mathrm{b}}$ Department of Anatomy and Neurobiology, University of Kentucky, Lexington, KY 40536, USA \\ ${ }^{c}$ Department of Surgery, University of Kentucky, Lexington, KY 40536, USA
}

Accepted 15 April 1997

\begin{abstract}
Previous studies have suggested that the neurotrophins brain-derived neurotrophic factor (BDNF) and neurotrophin-3 (NT-3) are neuroprotective or neurotrophic for certain subpopulations of hippocampal neurons following various brain insults. In the present study, the expression of BDNF and NT-3 mRNAs in rat hippocampus was examined after traumatic brain injury. Following lateral fluid percussion (FP) brain injury of moderate severity (2.0-2.1 atm) or sham injury, the hippocampi from adult rats were processed for the in situ hybridization localization of BDNF and NT-3 mRNAs using ${ }^{35}$ S-labeled cRNA probes at post-injury survival times of $1,3,6,24$ and $72 \mathrm{~h}$. Unilateral FP injury markedly increased hybridization for BDNF mRNA in the dentate gyrus bilaterally which peaked at $3 \mathrm{~h}$ and remained above control levels for up to $72 \mathrm{~h}$ post-injury. A moderate increase in BDNF mRNA expression was also observed bilaterally in the CA3 region of the hippocampus at 1, 3, and 6 h after FP injury, but expression declined to control levels by 24 h. Conversely, NT-3 mRNA was significantly decreased in the dentate gyrus following FP injury at the 6 and 24 h survival times. These results demonstrate that FP brain injury differentially modulates expression of BDNF and NT-3 mRNAs in the hippocampus, and suggest that neurotrophin plasticity is a functional response of hippocampal neurons to brain trauma. (C) 1997 Elsevier Science B.V.
\end{abstract}

Keywords: Traumatic brain injury; Lateral fluid percussion; Brain-derived neurotrophic factor; Neurotrophin-3; Hybridization, in situ; Neuronal plasticity

Secondary or delayed injury processes that begin to develop within minutes and continue to develop for hours after traumatic brain injury can contribute to irreversible tissue damage [3]. Although the sequence and timing of these processes are largely unknown, they are thought to be initiated by the release of neurotransmitters such as excitatory amino acids $[8,23,35,37]$ and acetylcholine [14], and by the subsequent activation of neurotransmitter receptors, including NMDA-receptor subtypes, muscarinic cholinergic receptors, and opioid receptors [6,16,29,38]. An increase in intracellular calcium and the subsequent stimulation of calcium-dependent enzymatic activities are implicated mediators in some of the neurotransmitter-

\footnotetext{
* Corresponding author. Department of Anatomy and Neurobiology, University of Kentucky, Lexington, KY 40536-0084, USA. Fax: + 1 (606) 323-5946.

${ }^{1}$ Present address: Department of Molecular Psychiatry, Yale University School of Medicine, New Haven, CT 06508, USA.
}

induced generation of secondary injury factors $[6,10,16,19,45]$.

Several studies indicate that activation of excitatory amino-acid receptors in neurons can also result in the induction of neurotrophic factors, such as nerve growth factor (NGF) and brain-derived neurotrophic factor (BDNF) [34,47] (for review, see [26]). Accordingly, increased gene expression for BDNF and NGF in the brain has been observed in several models of central nervous system injury, such as ischemia and seizures, where excitatory amino-acid receptors are implicated in the pathogenesis $[12,21,27,46]$. In contrast to the up-regulation of NGF and BDNF mRNAs, down-regulation of neurotrophin-3 (NT-3) mRNA has also been observed with cerebral ischemia and seizures [12,27]. It has been suggested that these neurotrophins may provide neuroprotection by playing a role in the maintenance and survival of neurons after traumatic brain injury $[31,33]$. Therefore, it is important to characterize the spatial and temporal patterns and levels of neurotrophic factor expression after experimental brain injury. 
Relatively few studies have examined alterations in the neurotrophin family of trophic factors after traumatic brain injury. Recent reports have, however, demonstrated increases of BDNF and NGF mRNAs and NGF protein in cortical areas after cortical contusion brain injury $[5,15,48]$. The present study characterized the changes in BDNF and NT-3 mRNAs in the hippocampus after lateral fluid percussion (FP) brain injury, another established model of traumatic brain injury. The hippocampus was of particular interest because of its prominent expression of and responsiveness to neurotrophins [2,13,22,25], its vulnerability to neurodegeneration subsequent to various brain insults [41], and its role in learning and memory dysfunction following FP injury [18,44].

Male Sprague-Dawley rats (325-350 g) were anesthetized with sodium pentobarbital $(60 \mathrm{mg} / \mathrm{kg}$ i.p. $) 10 \mathrm{~min}$ after receiving $0.15 \mathrm{ml}$ of atropine $(0.4 \mathrm{mg} / \mathrm{ml}$ i.m. $)$, and placed in a stereotaxic frame. The scalp and temporal muscles were reflected, and a stainless-steel screw was secured to the skull $1 \mathrm{~mm}$ anterior to bregma. A hand-held trephine with a $4.9 \mathrm{~mm}$ diameter was used to make a craniotomy, which was centered between bregma and lambda, $3 \mathrm{~mm}$ lateral to the sagittal suture. A Luer-loc hub was rigidly fixed with dental cement to the craniotomy. Experimental lateral FP brain injury of moderate severity (2.0-2.1 atm) was induced in the anesthetized animals $(n=20)$ using a well-characterized model that has been previously described in detail [20,32]. Following FP injury, rats were allowed to survive for $1,3,6,24$ or $72 \mathrm{~h}$ before euthanasia, in order to assess the acute response of the neurotrophins to the injury. A subset of animals $(n=4 ; 3$ $h$ survival period) underwent anesthesia and surgery but were not injured (sham treatment).

After the appropriate survival times, the rats were deeply anesthetized with an overdose of sodium pentobarbital and decapitated. Brains were rapidly removed and frozen over dry ice. Tissue sections through the hippocampus were cut in the coronal plane at $10 \mu \mathrm{m}$ in a cryostat, thaw-mounted onto Superfrost Plus (Curtin Matheson Scientific) glass slides, and stored at $-20^{\circ} \mathrm{C}$ until processing for hybridization. Adjacent sections throughout the hippocampus of animals from the various injury and sham groups were processed for the in situ hybridization localization of $\mathrm{mR}$ NAs for BDNF and NT-3 as previously described $[11,42,43]$. The cRNA probes were prepared by in vitro transcription from linearized cDNA constructs with the appropriate RNA polymerase in the presence of $\left[{ }^{35} \mathrm{~S}\right] \mathrm{UTP}$. The 550-base rat NT-3 cRNA is complementary to 392 bases of the mature rat NT-3 coding region, whereas the 540-base BDNF cRNA includes 384 bases complementary to the rat BDNF mRNA coding region [11,21]. Hybridization was conducted at $60^{\circ} \mathrm{C}$ for $18-24 \mathrm{~h}$ with the ${ }^{35} \mathrm{~S}$ labeled cRNA at a concentration of $1 \times 10^{6} \mathrm{cpm} / 50$ $\mu \mathrm{l} /$ slide. Following post-hybridization washes and ribonuclease treatment, the sections were air-dried and exposed to $\beta$-Max Hyperfilm (Amersham) for 14-18 days at room temperature for generation of film autoradiograms. After autoradiographic film development, the sections were dipped in NTB2 nuclear track emulsion (Kodak; 1:1 in $\mathrm{H}_{2} \mathrm{O}$ ), air-dried, and exposed in light-tight boxes at $4^{\circ} \mathrm{C}$ for 4-6 weeks. After autoradiographic development of the emulsion, the sections were counterstained with Cresyl violet, coverslipped in D.P.X. mounting medium (Fluka), and analyzed with a Nikon Optiphot-2 microscope equipped with brightfield and darkfield optics. Cells were considered labeled if the density of reduced silver grains overlying the perikarya was at least 10-fold greater than background. Control sections that had been treated with ribonuclease A $\left(45^{\circ} \mathrm{C}\right.$ for $30 \mathrm{~min}$ ) before hybridization or processed for hybridization with appropriate sense-strand riboprobes (see [11]) were devoid of specific labeling.

Film autoradiograms were analyzed with Image 1.50 software (NIH) to compare the density of hybridization for the neurotrophin mRNAs in various hippocampal subfields (dentate gyrus, CA1 and CA3) after sham treatment to that found after the various survival periods following lateral FP injury. Three to seven sections were analyzed per animal. All measurements are expressed as the mean \pm S.E.M values. The data sets were compared using a twoway analysis of variance (ANOVA) for side (ipsilateral and contralateral to the injury) and groups (5 injury survival times and sham treatment). Newman-Keuls post-hoc analyses were used for pairwise comparisons with a significance level set at $P<0.05$. BDNF and NT-3 mRNA levels did not differ by side for any of the hippocampal regions investigated, nor was there a side by group interaction (data not shown). Therefore, the hybridization data from the ipsilateral and contralateral sides were combined. The mean value of the sham control ( $3 \mathrm{~h}$ survival) was also compared to additional sham treatment animals with survival periods of $1,6,24$, and $72 \mathrm{~h}(n=3 /$ group $)$ post-surgery. No significant differences were found in hybridization densities among sham treatment groups with various survival periods for either BDNF or NT-3 mRNAs in any of the hippocampal subfields (data not shown).

Hybridization for BDNF mRNA was present in the granule cell layer of the dentate gyrus (stratum granulosum) and in regions CA1-CA3 of the hippocampus in the control (sham treatment) animals (Fig. 1A), similar to previous reports in normal, uninjured rats [7,21]. Unilateral FP injury resulted in a marked bilateral increase in the expression of BDNF mRNA in the dentate gyrus granule cell layer, which peaked at $3 \mathrm{~h}$ and remained above control levels for up to $72 \mathrm{~h}$ after injury (Fig. 1B-D). Densitometric measurements of film autoradiograms demonstrated that BDNF mRNA hybridization was significantly increased in the granule cell layer at all post-injury time points ( $P<0.001$; Fig. 2A). Expression of BDNF mRNA was also significantly elevated bilaterally in the hippocampal CA3 region at 1,3 and $6 \mathrm{~h}$ after FP injury $(P<0.001)$, but returned to control levels by $24 \mathrm{~h}$ (Figs. 1 and 2B). Again, the most pronounced increase in labeling in the 
BDNF
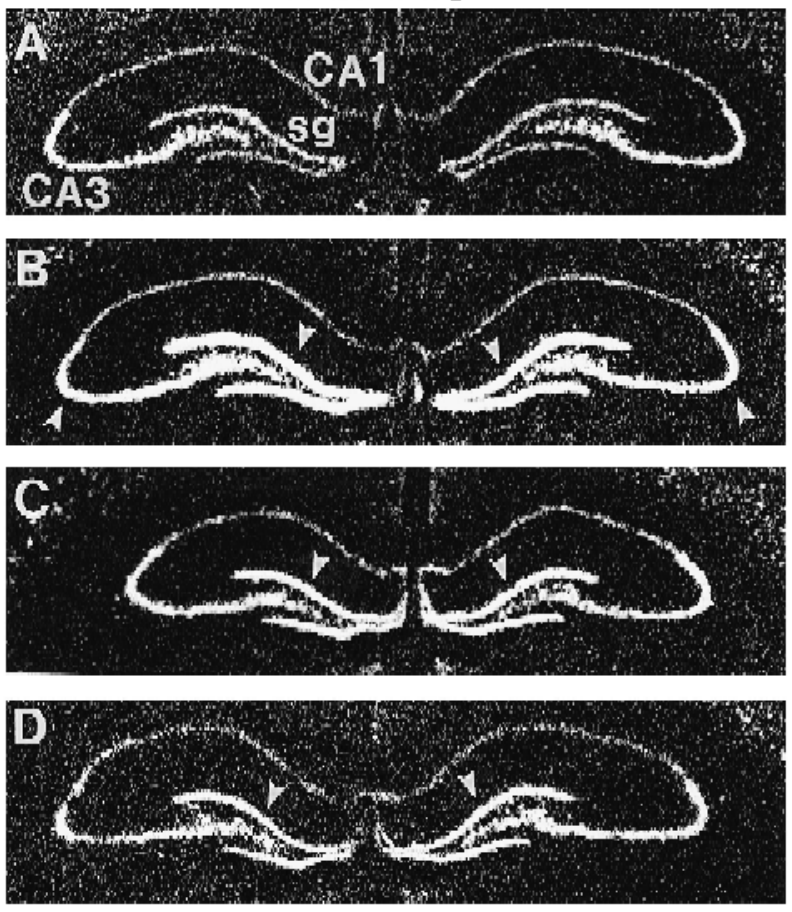

NT -3
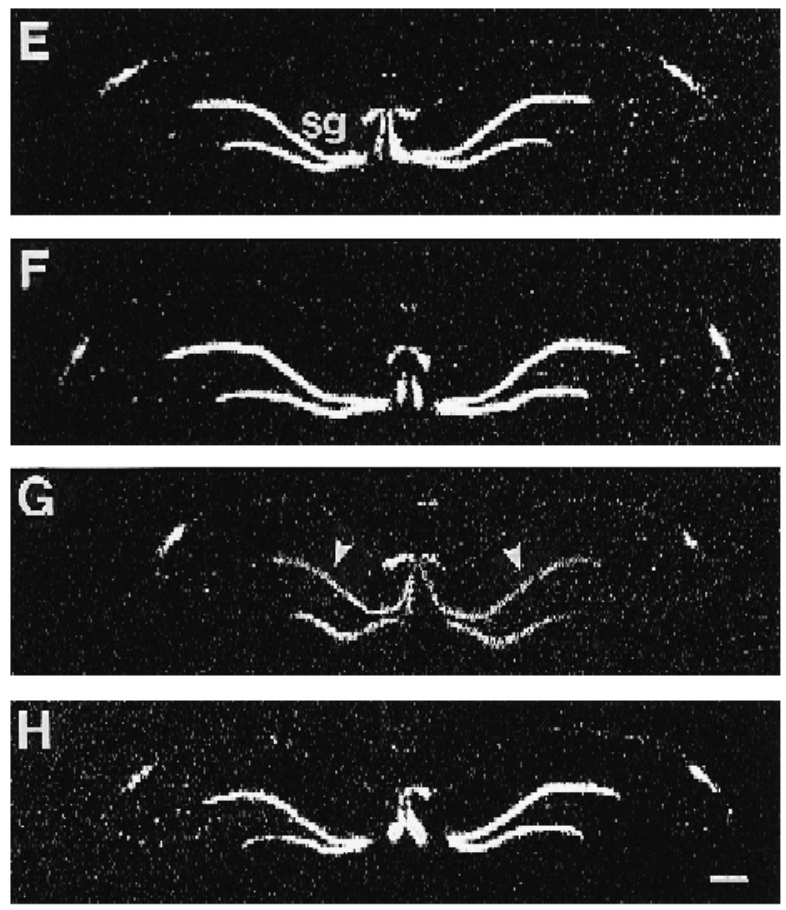

Fig. 1. Prints of film autoradiograms showing expression of BDNF (A-D) and NT-3 (E-H) mRNAs in coronal sections from control (sham) rats (A,E), and from rats subjected to moderate unilateral FP brain injury with $3(\mathrm{~B}, \mathrm{~F}), 24(\mathrm{C}, \mathrm{G})$, and $72 \mathrm{~h}(\mathrm{D}, \mathrm{H})$ survival periods. Note the increased hybridization for BDNF mRNA bilaterally in the dentate gyrus granule cell layer (stratum granulosum; sg) at all survival times following injury (B-D), and in the hippocampal CA3 region at the $3 \mathrm{~h}$ post-injury time point (B). In contrast, NT-3 mRNA levels are decreased bilaterally in the dentate gyrus at $24 \mathrm{~h}$ post-injury (G). Arrowheads in appropriate panels indicate the cell layers and survival times which differ significantly from the sham controls (see quantification in Figs. 2 and 3). Scale bar $=500 \mu \mathrm{m}$.
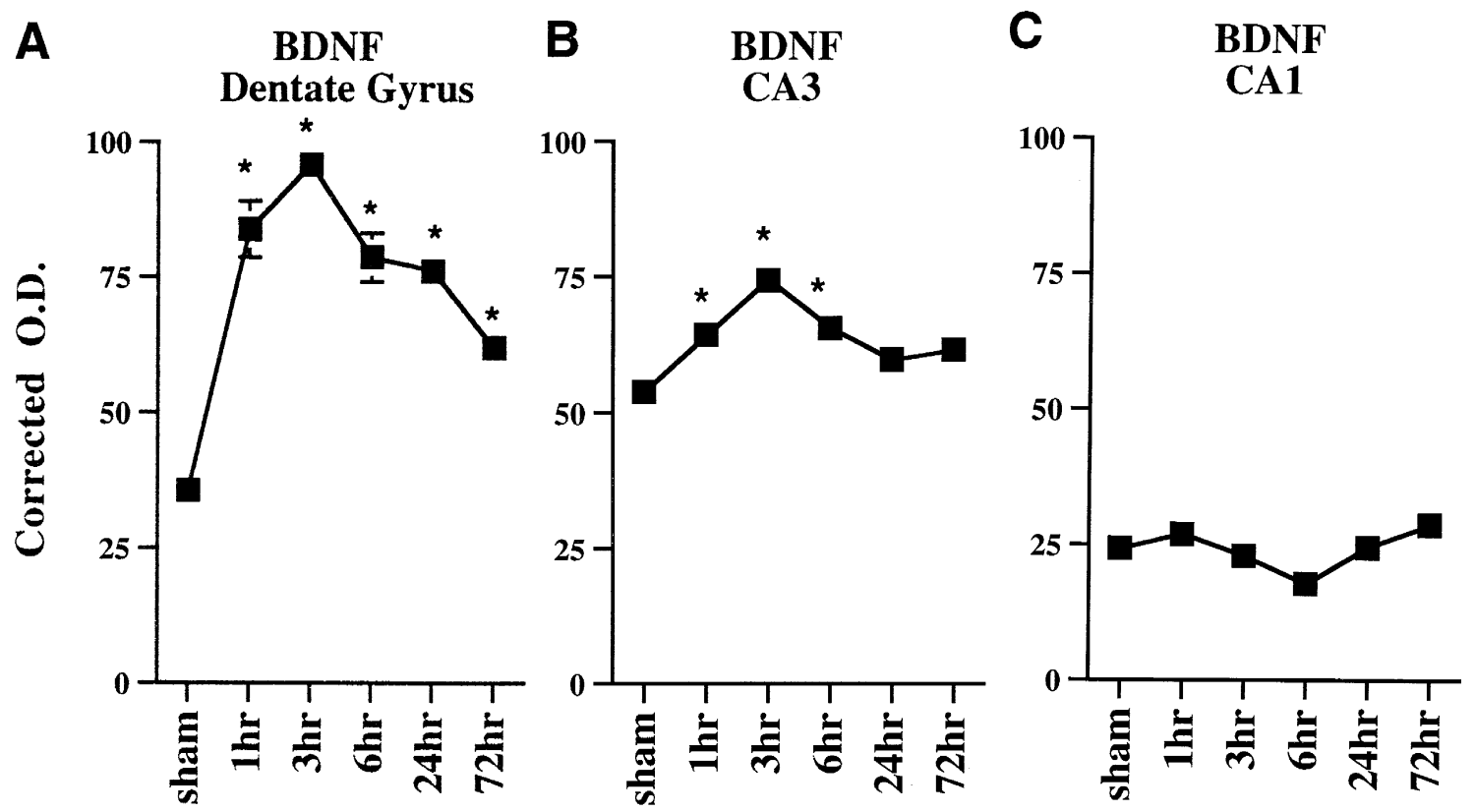

Fig. 2. Graphs showing corrected optical density (O.D.) measurements of hybridization for BDNF mRNA in the dentate gyrus stratum granulosum (A), hippocampal CA3 (B), and hippocampal CA1 (C) regions over time following lateral FP brain injury. Note the significant increase in BDNF mRNA expression in the dentate gyrus granule cell layer at all post-injury times (A), and in the hippocampal CA3 region at 1, 3, and $6 \mathrm{~h}$ following injury (B), compared to the sham treatment group $\left({ }^{*} P<0.001\right)$. Lateral FP injury did not alter BDNF mRNA levels in the hippocampal CA1 region at any of the survival times $(C)$. Values represent mean \pm S.E.M. 
CA3 region was evident at $3 \mathrm{~h}$ after injury (Fig. 1B). No changes in expression of BDNF mRNA occurred in the CA1 region of the hippocampus following FP injury (Figs. 1 and $2 \mathrm{C})$.

In the control, sham-injured animals the most prominent expression of NT-3 mRNA was localized to the dentate gyrus granule cell layer (Fig. 1E). Labeled cells were also present in regions CA2 and extreme medial CA1 of the hippocampal pyramidal cell layer, as well as infrequently scattered throughout the dentate gyrus hilus and hippocampal molecular layers (Fig. 1E). This distribution is in good agreement with previous descriptions in normal rats [7,13]. Following unilateral FP injury, hybridization for NT-3 mRNA was decreased bilaterally in the dentate gyrus granule cell layer at the 6 and $24 \mathrm{~h}$ survival times (Fig. $1 \mathrm{G})$. By $72 \mathrm{~h}$ post-injury, hybridization levels had returned to near-control (sham injury) levels (Fig. 1H). Quantitative measurements of film autoradiograms confirmed that NT-3 mRNA expression was significantly reduced in the granule cells at both 6 and $24 \mathrm{~h}$ after FP injury $(P<0.001$; Fig. 3$)$, compared to sham controls. Although not analyzed densitometrically, visual examination of NT-3 mRNA hybridization in CA2 and medial CA1 indicated no apparent change in expression at any of the survival times post-injury, compared to sham controls.

The present results demonstrate that FP brain injury induces pronounced alterations in the expression of neurotrophin mRNAs in the hippocampus. Levels of BDNF mRNA were substantially increased post-injury in both the dentate gyrus granule cell and CA3 pyramidal cell layers. In contrast, expression of NT-3 mRNA was transiently

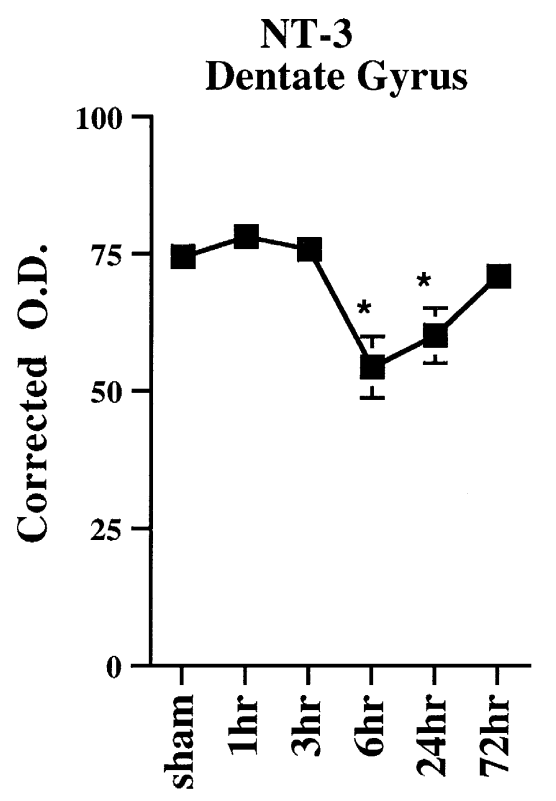

Fig. 3. Graph showing corrected optical density (O.D.) measurements of NT-3 mRNA hybridization in the dentate gyrus granule cell layer over time following lateral FP brain injury. Note the significant decline in NT-3 mRNA expression at 6 and $24 \mathrm{~h}$ after injury compared to the sham treatment group ( $\left.{ }^{*} P<0.001\right)$. Values represent mean \pm S.E.M. decreased in the dentate gyrus, and the response was delayed relative to the early change in BDNF. Thus, traumatic brain injury differentially modulates neurotrophin gene expression in the hippocampus, in patterns and directions similar to findings in other brain injury paradigms including ischemia and seizures [12,13,27,28]. Although the present study focused on the hippocampal formation, it should be noted that obvious alterations in neurotrophin expression following FP injury were also observed in other brain regions, including the cortical lesion site, adjacent neocortical areas, the piriform cortex, and several medial thalamic nuclei (data not shown).

Our results are consistent with recent data on the acute modulation of neurotrophin gene expression obtained with another model of traumatic brain injury, the cortical contusion impact model [48]. That study reported an increase in BDNF, but no change in NT-3, mRNA levels in the dentate gyrus granule and hippocampal pyramidal cell layers at 1,3 , and $5 \mathrm{~h}$ (the longest survival time examined) post-injury. The lack of change in NT-3 mRNA expression may reflect the acute time course of their study, since in the present study the decrease in NT-3 expression was not evident until $6 \mathrm{~h}$ after FP injury. In any event, it is now apparent from two different paradigms that a consistent response of hippocampal neurons to traumatic brain injury is dramatic, differential regulation of neurotrophin expression.

The bilateral alterations in BDNF and NT-3 expression are in contrast to the gross morphological and histological damage which has been primarily identified in hippocampal regions ipsilateral to the impact site $[4,20]$. However, they are consistent with more subtle changes, such as the bilateral loss of hilar neurons [30] and bilateral alterations in the expression of immediate-early genes and tumor necrosis factor- $\alpha[9,39]$, which have been observed following unilateral FP injury. Whereas no evidence of abnormal behavior or overt seizure activity was noted in any of the experimental groups in this study, nor in a previous study with FP injury of this severity [30], it is possible that post-traumatic subclinical seizures contributed to the alterations in expression of BDNF and NT-3. However, neurochemical changes that would be expected to occur bilaterally following seizures have only been observed unilaterally following FP brain injury $[6,36,38]$.

The significance of the alterations in BDNF and NT-3 expression on cell survival following lateral FP injury is unclear. The dentate gyrus showed the greatest increase in BDNF compared to control values and cells in this region are selectively resistant to cell death following lateral FP injury $[4,20,30]$. However, BDNF expression was also elevated bilaterally in the hippocampal CA3 region, which contains numerous injured neurons on the side ipsilateral to the impact $[4,20]$. Numerous previous studies have supported the hypothesis that BDNF is neuroprotective following injury $[1,2,17,27,28,46]$, whereas others have found no trophic effect [40] or an actual increase in 
neuronal death [24] with BDNF treatment. Although further studies are necessary to clarify the role of BDNF following injury, one hypothesis is that it is the amount of BDNF available that is critical for promoting cell survival. The functional consequences of the concurrent decrease in NT-3 expression in the same cells (stratum granulosum) marked by the BDNF increase, also remain unknown. It is possible that whereas optimal neurotrophin levels may promote survival, insufficient or excessive levels may exacerbate neuronal loss. Moreover, injury-induced alterations in levels and functional states of appropriate neurotrophin receptors may also be important determinants of resulting neurotrophic functions.

In conclusion, lateral FP brain injury differentially modulates expression of BDNF and NT-3 in hippocampal neurons. These alterations are consistent with the hypothesis that widespread secondary events, including neurotrophin plasticity, occur following traumatic brain injury. Further investigations are necessary to evaluate the role of these neurotrophic factors on cell survival after experimental brain trauma.

\section{Acknowledgements}

The authors thank John Dose and Kerstin Lundgren for excellent technical assistance and Dr. James Herman for valuable comments on the manuscript. This work was supported by DOD Grant DAMD17-97-1-7011 (R.R.H.) and NIH Grants NS31816 (M.R.P.) and NS35164 (K.B.S.). S.N. was supported by NIMH Fellowship MH10806. In this study we carefully adhered to the animal welfare guidelines set forth by the Institutional Animal Care and Use Committee at the University of Kentucky and the Guide for the Care and Use of Laboratory Animals from the US Department of Health and Human Services.

\section{References}

[1] M. Ballarin, P. Ernfors, N. Lindefors, H. Persson, Hippocampal damage and kainic acid injection induce a rapid increase in mRNA for BDNF and NGF in the rat brain, Exp. Neurol. 114 (1991) 35-43.

[2] B. Cheng, M.P. Mattson, NT-3 and BDNF protect CNS neurons against metabolic/excitotoxic insults, Brain Res. 640 (1994) 56-67.

[3] P.R. Cooper, Delayed brain injury: secondary insults. In D.P. Becker and J.T. Povlishock (Eds.), Central Nervous System Trauma Status Report, National Institute of Neurological and Communicative Disorders and Stroke, National Institutes of Health, Bethesda, MD, 1985, pp. 217-228.

[4] S. Cortez, T. McIntosh, L. Noble, Experimental fluid percussion brain injury: vascular disruption and neuronal and glial alterations, Brain Res. 482 (1989) 271-282.

[5] S.T. DeKosky, J.R. Goss, P.D. Miller, S.D. Styren, P.M. Kochanek, D. Marion, Upregulation of nerve growth factor following cortical trauma, Exp. Neurol. 130 (1994) 173-177.

[6] H.S. Dhillon, T. Carbary, J. Dose, R.J. Dempsey, M.R. Prasad, Activation of phosphatidylinositol bisphosphate signal transduction pathway after experimental brain injury: a lipid study, Brain Res. 698 (1995) 100-106.
[7] P. Ernfors, C. Wetmore, L. Olson, H. Persson, Identification of cells in the rat brain and peripheral tissues expressing mRNA for members of the nerve growth factor family, Neuron 5 (1990) 511-526.

[8] A.I. Faden, P. Demediuk, S.S. Panter, R. Vink, The role of excitatory amino acids and NMDA receptors in traumatic brain injury, Science 244 (1989) 798-800.

[9] L. Fan, P.R. Young, F.C. Barone, G.Z. Feuerstein, D.H. Smith, T.K. McIntosh, Experimental brain injury induces differential expression of tumor necrosis factor- $\alpha$ mRNA in the CNS, Mol. Brain Res. 36 (1996) 287-291.

[10] I. Fineman, D.A. Hovda, M. Smith, A. Yoshino, D.A. Becker, Concussive brain injury is associated with a prolonged accumulation of calcium: a ${ }^{45} \mathrm{Ca}$ autoradiographic study, Brain Res. 624 (1993) 94-102.

[11] C.M. Gall, S.J. Gold, P.J. Isackson, K.B. Seroogy, Brain-derived neurotrophic factor and neurotrophin-3 mRNAs are expressed in ventral midbrain regions containing dopaminergic neurons, Mol. Cell. Neurosci. 3 (1992) 56-63.

[12] C.M. Gall, Seizure-induced changes in neurotrophin expression: implications for epilepsy, Exp. Neurol. 124 (1993) 150-166.

[13] C.M. Gall and J.C. Lauterborn, Dentate gyrus as a model system for studies of neurotrophic factor regulation in the CNS: seizure studies. In C.E. Ribak, C.M. Gall and I. Mody (Eds.), The Dentate Gyrus and its Role in Seizures, Elsevier, Amsterdam, The Netherlands, 1992, pp. 171-185.

[14] L.K. Gorman, K. Fu, D.A. Hovda, D.P. Becker, Y. Katayama, Analysis of acetylcholine release following concussive brain injury in the rat, J. Neurotrauma 6 (1989) 203-207.

[15] J.R. Goss, S.D. Styren, P.D. Miller, P.M. Kochanek, A.M. Palmer, D.W. Marion, S.T. DeKosky, Hypothermia attenuates the normal increase in interleukin 1B RNA and nerve growth factor following traumatic brain injury in the rat, J. Neurotrauma 12 (1995) 159-167.

[16] R.L. Hayes, L.W. Jenkins, B.G. Lyeth, Neurotransmitter-mediated mechanisms of traumatic brain injury: acetylcholine and excitatory amino acids, J. Neurotrauma 9 (1992) S173-S187.

[17] R.L. Hayes, K. Yang, J.S. Whitson, J.J. Xue, A. Kampfl, X.S. Mu, X. Zhao, F. Faustinella, G.L. Clifton, Rescue of injury-induced neurofilament loss by BDNF gene transfection in primary septo-hippocampal cell cultures, Neurosci. Lett. 191 (1995) 121-125.

[18] R.R. Hicks, D.H. Smith, D.H. Lowenstein, R. Saint Marie, T.K. McIntosh, Mild experimental brain injury in the rat induces cognitive deficits associated with regional neuronal loss in the hippocampus, J. Neurotrauma 10 (1993) 405-414.

[19] R.R. Hicks, D.H. Smith, T.K. McIntosh, Temporal response and effects of excitatory amino acid antagonism on microtubule-associated protein 2 immunoreactivity following experimental brain injury in rats, Brain Res. 678 (1995) 151-160.

[20] R.R. Hicks, H.D. Soares, D.H. Smith, T.K. McIntosh, Temporal and spatial characterization of neuronal injury following lateral fluid-percussion brain injury in the rat, Acta Neuropathol. 91 (1996) 236-246.

[21] P.J. Isackson, M.M. Huntsman, K.D. Murray, C.M. Gall, BDNF mRNA expression is increased in adult rat forebrain after limbic seizures: temporal patterns of induction distinct from NGF, Neuron 6 (1991) 937-948.

[22] P.J. Isackson, Trophic factor response to neuronal stimuli or injury, Curr. Opin. Neurobiol. 5 (1995) 350-357.

[23] Y. Katayama, D.P. Becker, T. Tamura, D.A. Hovda, Massive increases in extracellular potassium and the indiscriminate release of glutamate following concussive brain injury, J. Neurosurg. 73 (1990) 889-900.

[24] J.Y. Koh, B.J. Gwag, D. Lobner, D.W. Choi, Potentiated necrosis of cultured cortical neurons by neurotrophins, Science 268 (1995) $573-575$.

[25] Z. Kokaia, A. Othberg, M. Kokaia, O. Lindvall, BDNF makes cultured dentate granule cells more resistant to hypoglycaemic damage, NeuroReport 5 (1994) 1241-1244.

[26] D. Lindholm, E. Castrén, M. Berzaghi, A. Blochl, H. Thoenen, 
Activity-dependent and hormonal regulation of neurotrophin mRNA levels in the brain: implications for neuronal plasticity, J. Neurobiol. 25 (1994) 1362-1372.

[27] O. Lindvall, P. Ernfors, J. Bengzon, Z. Kokaia, M.L. Smith, B.K. Siesjö, H. Persson, Differential regulation of mRNAs for nerve growth factor, brain-derived neurotrophic factor and neurotrophin-3 in the adult rat brain following cerebral ischemia and hypoglycemic coma, Proc. Natl. Acad. Sci. USA 89 (1992) 648-652.

[28] O. Lindvall, Z. Kokaia, J. Bengzon, E. Elmer, M. Kokaia, Neurotrophins and brain insults, Trends Neurosci. 17 (1994) 490-496.

[29] B.G. Lyeth, R.L. Hayes, Cholinergic and opioid mediation of traumatic brain injury, J. Neurotrauma 9 (1992) S463-S474.

[30] D.H. Lowenstein, M.J. Thomas, D.H. Smith, T.K. McIntosh, Selective vulnerability of dentate hilar neurons following TBI: a potential mechanistic link between head trauma and disorders of the hippocampus, J. Neurosci. 12 (1992) 4846-4853.

[31] M.P. Mattson, S.W. Scheff, Endogenous neuroprotection factors and traumatic brain injury: mechanisms of action and implications for therapy, J. Neurotrauma 11 (1994) 3-33.

[32] T.K. McIntosh, R. Vink, L. Noble, I. Yamakami, S. Fernyak, H. Soares, A.I. Faden, Traumatic brain injury in the rat: characterization of a lateral fluid-percussion model, Neuroscience 28 (1989) 233-244.

[33] I. Mochetti, J.R. Wrathall, Neurotrophic factors and central nervous system trauma, J. Neurotrauma 12 (1995) 853-870.

[34] K.D. Murray, P.L. Wood, C. Rosasc, P.J. Isackson, A metabotropic glutamate receptor agonist regulates neurotrophin messenger RNA in rat forebrain, Neuroscience 70 (1996) 617-630.

[35] P. Nilsson, L. Hillered, U. Ponten, U. Ungerstedt, Changes in cortical extracellular levels of energy-related metabolites and amino acids following concussive brain injury in rats, J. Cereb. Blood Flow Metab. 10 (1990) 631-637.

[36] B. Padmaperuma, H.S. Dhillon, T. Carbary, M.R. Prasad, Alterations in brain protein kinase $\mathrm{C}$ after experimental brain injury, Brain Res. 714 (1996) 19-26.

[37] A.M. Palmer, D.W. Marion, M.L. Botscheller, P.E. Swedlow, S.D. Styren, S.T. DeKosky, Traumatic brain injury-induced excitotoxicity assessed in a controlled cortical impact model, J. Neurochem. 61 (1993) 2015-2024.

[38] M.R. Prasad, H.S. Dhillon, T. Carbary, R.J. Dempsey, S.W. Scheff, Enhanced phosphodiestric breakdown of phosphatidylinositol bis- phosphate after experimental brain injury, J. Neurochem. 63 (1994) $773-776$.

[39] R. Raghupathi, T.K. McIntosh, Regionally and temporally distinct patterns of induction of c-fos, c-jun and junB mRNAs following experimental brain injury in the rat, Mol. Brain Res. 37 (1996) 134-144.

[40] J.S. Rudge, E.M. Pasnikowski, P. Holst, R.M. Lindsay, Changes in neurotrophic factor expression following exposure of hippocampal neuron/astrocyte cocultures to kainic acid, J. Neurosci. 15 (1995) 6856-6867.

[41] S.S. Schreiber, M. Baudry, Selective neuronal vulnerability in the hippocampus - a role for gene expression?, Trends Neurosci. 18 (1995) 446-451.

[42] K.B. Seroogy, K.H. Lundgren, T.M.D. Tran, K.M. Guthrie, P.J. Isackson, C.M. Gall, Dopaminergic neurons in rat ventral midbrain express brain-derived neurotrophic factor and neurotrophin-3 mRNAs, J. Comp. Neurol. 342 (1994) 321-334.

[43] K.B. Seroogy and J.P. Herman, In situ hybridization approaches to the study of the nervous system. In A.J. Turner and H.S. Bachelard (Eds.), Neurochemistry: A Practical Approach, 2nd edn., Oxford University Press, Oxford, UK, 1997, pp. 121-150.

[44] D.H. Smith, K. Okiyama, M.J. Thomas, B. Claussen, T.K. McIntosh, Evaluation of memory dysfunction following experimental brain injury using the Morris water maze, J. Neurotrauma 8 (1991) 259-269.

[45] W.C. Taft, K. Yang, C.E. Dixon, R.L. Hayes, Microtubule-associated protein 2 levels decrease in hippocampus following traumatic brain injury, J. Neurotrauma 9 (1992) 281-290.

[46] T. Tsukahara, Y. Yonekawa, K. Tanaka, O. Ohara, S. Watanabe, T. Kimura, T. Nishijima, T. Taniguchi, The role of brain-derived neurotrophic factor in transient forebrain ischemia in the rat brain, Neurosurgery 34 (1994) 323-331.

[47] C. Wetmore, L. Olson, A.J. Bean, Regulation of brain-derived neurotrophic factor (BDNF) expression and release from hippocampal neurons is mediated by non-NMDA type glutamate receptors, J. Neurosci. 14 (1994) 1688-1700.

[48] K. Yang, J.R. Perez-Polo, X.S. Mu, H.Q. Yan, J.J. Xue, Y. Iwamoto, S.J. Liu, C.E. Dixon, R.L. Hayes, Increased expression of brain-derived neurotrophic factor but not neurotrophin-3 mRNA in rat brain after cortical impact injury, J. Neurosci. Res. 44 (1996) 157-164. 